\title{
WAYS OF TEACHING AND LEARNING ENGLISH LANGUAGE IN ORDER TO IMPROVE GEOGRAPHIC KNOWLEDGE
}

\author{
DANIELA LARION \\ "Alexandru Ioan Cuza" University, Iași, Romania, Faculty of Geography and Geology, Department of \\ Geography, e-mail: danielalarion@yahoo.co.uk
}

\begin{abstract}
ANDRA-COSMINA ALBULESCU
"Alexandru Ioan Cuza" University, Iași, Romania, Faculty of Geography and Geology, Department of
\end{abstract} Geography, e-mail: cosminaalbulescu@yahoo.com

(Received: December 2017; in revised form: February 2018)

\begin{abstract}
The study of English language as a foreign language for the Geography students in the universities of Romania has an important role in students' professional development and in the integration of Romanian academic education in the international context. The implementation of the Bologna Process' international programmes in "Alexandru Ioan Cuza" University of Iași (including the Department of Geography), the exchange of students and teaching staff among universities from different countries, the worldwide dissemination of geographic research results require better knowledge of English language in the field of Geography. In such a context, in the Geography Department of "Alexandru Ioan Cuza" University of Iași, a new approach on teaching English language has been implemented since 2014, ELG (English Language for Geographers), a unique approach in Romania. This paper presents the characteristics and the advantages of this new way of teaching English language, materialised in the publication, in 2017, of a textbook for the Geography students, "English Language for Geography Students" (Daniela Larion), the first textbook of this kind in Romania.
\end{abstract}

Keywords: academic education, Geography students, ELG (English Language for Geographers), ESP (English for Special Purposes), CBI (Content Based Instruction) 


\section{INTRODUCTION}

What are the benefits of learning English language for Geography students? Learning a foreign language as a compulsory subject in the academic education, for the first and second year students in Geography, is a necessity and also an advantage for the professional growth of the specialists to be.

English language enables the assimilation and understanding of scientific information, with access to international publications, academic and scientific websites, giving the opportunity to be in touch with the latest achievements in the field of Geography.

English language is a necessary tool to apply to different international programmes, to cooperate with geographers and specialists worldwide, to become part of multinational research programmes, to get study scholarships in universities abroad.

English language is an almost compulsory tool one needs in order to use different computer programmes, applications, the Internet, in general, making the research activity more efficient. All the practical jobs we prepare our students for are more likely to be offered to those with good English knowledge, with specific jobs in which English language skills represent the basic requirement. It is the case of many jobs in tourism industry, air transport industry, different positions in multinational companies, or of jobs abroad.

English language is the queen of global communication, a link between countries and cultures, ensuring the connection between people coming from all over the world, contributing to the development of human interrelations.

Besides all these aspects, there are benefits on a personal level for those who study and constantly improve their English language, as this activity adds to their intellectual growth, developing their brain activity and making them more fit for performing challenging intellectual tasks.

Therefore, there is no way that learning English language could be useless, as, one way or the other, it will be necessary for those who learn it.

What are the ways in which Geography students learn English language?

The curriculum for the students of the Geography Department in "Alexandru Ioan Cuza" University of Iași includes one hour of lecture and two hours of seminar of English language per week, for three semesters (that is two semesters for the first year students and one semester for the second year ones). Attending these classes and taking the exams represent the official 
way in which Geography students can learn/improve their English knowledge. It is by interviewing 9 Ph.D. Geography students that we found out that regular classes of English language (prior to 2014) did not add much to their English language applied in the Geography field. For this reason, independent work and research and sometimes English courses taken outside the department were often necessary, considering that English language proficiency is a requirement for Ph.D. students in order to be accepted for the doctoral studies, and later on very much needed in the process of elaborating their thesis.

Other ways to improve English include application to international study or internship programmes (such as Erasmus+), and studying for one semester or more in a foreign university, where classes are taught in English, individual study, practising communication in English (with incoming Erasmus students and teaching staff), using social media and online reading, etc.

With this study, we focus on improving English language skills at the same time with geographic skills, through the English language course taught to Geography students, as part of their academic education.

\section{THEORETICAL BACKGROUND. INTEGRATING THE ELG CONCEPT IN THE PRESENT TYPOLOGY FOR LEARNING ENGLISH LANGUAGE}

The interest in developing better and more suitable ways of teaching English as a foreign language has been constantly growing in the last decades, due to the undoubtedly strengthening role of English language in a globalised world.

As the teaching approach we have been using in the Geography Department since 2014 does not fit in one single model, we call it English Language for Geographers (ELG) and we will show how it resembles or differs from other teaching models used for English teaching and learning.

Teaching and learning English language should adjust to the learners' purpose, to the reasons why they need this language (Irimiea, 2016), which means that teaching standard English in the traditional way is no longer the best choice. This is valid especially in tertiary education, where the field of study is clear and the purpose of learning English language can be adjusted to the practical needs. Our ELG approach was elaborated by considering the purposes our Geography students have in learning English language.

For more than five decades now, English for Specific Purpose (ESP) has been used for teaching English as a foreign language (Chalikandy, 2013). Initially, ESP was divided into two main branches, English for Academic Purpose (EAP) and English for Occupational Purpose (EOP), separation which does not seem to be so important in the field of 
Geography, due to the close connection between Geography education and work. Therefore, in ELG we combine EAP with EOP. In the first textbook we wrote (English Language for Geography Students, Daniela Larion, 2017), in terms of geographic content, we covered mainly the theoretical background in the science of Geography, with different applications and assignments on the practical/occupational aspects, while in the second book we are writing now, it is mainly the EOP that is being covered.

An interesting approach used in teaching English refers to the advantages of teaching English language in correlation with another subject, which is called Content Based Instruction (CBI) (Brinton et al., 1989; Dueňas, 2004; Corrales and Maloof, 2011). The implementation of CBI in English language learning to Molecular Microbiology has been studied by Florez et al. (2011), and the results showed an improvement in the English language skills of the students who took CBI classes. An important requirement in $\mathrm{CBI}$ is the good cooperation between the content teacher and the language teacher, as the language teacher alone cannot fulfil this job. From this point of view, ELG is more than CBI, as the content teacher and the language teacher is one and the same. This represents a huge advantage, in our opinion, as it is the same teacher who can ensure a balance between the two learning components, by deciding when and how one or the other aspect should be dominant.

As a practical example of creating a lesson framework in CBI, a three-stage process was developed (Brinton and Holten, 1997). The first stage is called into (when the activities are focused on the knowledge the students already have in that field), the second stage is called through (when the new content is introduced to the students), and the third stage is called beyond (when the activities aim at demonstrating the mastery of the content and language). This three-stage process is often integrated in our ELG classes, with good results.

The concept of Content and Language Integrated Learning (CLIL), introduced in 1994 by David Marsh, refers to using a second language (a foreign language) to teach specific content. This is the teaching approach used in the Department of Geography (Alexandru Ioan Cuza University of Iași) to teach the curriculum subjects to the students of the Geography of Tourism in French specialisation, a clear content-oriented approach. In a couple of years, the same CLIL approach will be used to teach all subjects at the Geography of Tourism in English specialisation, which is being prepared and organised to set up. CLIL is based on learning a specific subject-matter in a foreign language or learning it through a foreign language, so it is not appropriate for teaching English language in our ELG approach.

One teaching approach that partially fits in our ELG concept is the CBI adjunct model (Met, 1999, cited by Banegas, 2012), and it can be used in the academic education, where the main purpose is to master scientific content and improve language skills at the same time. Usually, according to the purpose of learning, the models used so far are either content-driven or 
language-driven. In our ELG approach, although it seems like we use a language-driven teaching, we tend to give significant importance to the content when the information is absolutely compulsory and basic to the Geography students. In this respect, many assignments we give to the students and many exercises in the class aim at evaluating both aspects.

A Language Triptych (developed by Coyle, 1990 and cited by Banegas, 2012) shows how languages can be learnt. One approach is the emphasis on learning the vocabulary and phrases to access the content (language of learning); the second approach requires a certain vocabulary to perform more advanced tasks like debating, explaining, analysing information (language for learning); the third approach includes the unplanned language aspects that rise from the cognitive activity of the students during the class (language through learning). According to the type of lesson, to the difficulty of the content, to the English level of the students, all these three steps of learning English language are being used in teaching ELG.

Teaching a foreign language using CLT (Communicative Language Teaching) or GTM (Grammar Translation Method) has been in debate for a long time, with pros and cons for each of them. Ahmad and Rao (2013) concluded in their study that CLT was more efficient in teaching English language in the secondary education in Pakistan, as both students and teachers were more open and motivated to use that approach, therefore, the results were better. Another study on the efficiency of GTM and CTL in teaching English language (Memon et al., 2016) appreciated that GTM was more efficient in $60 \%$ of the cases, while in $40 \%$ of the cases, CTL was considered more useful. Our ELG approach combines both methods, as they clearly complement each other in the process of teaching and learning English language for Geography students. There are situations when CLT is more appropriate (especially for the students attending Geography of Tourism studies). The teaching methods in ELG are chosen in accordance with the language skills that are targeted to be improved (writing skills, reading skills, speaking skills, and listening skills).

We may conclude that ELG represents an original approach of teaching and learning English as a foreign language, a sort of a hybrid originating in the CBI and ESP, but clearly developing independently and uniquely, using many tools of Geography teaching which are not only very familiar to the learners but also prove to be a more efficient way of accomplishing the goals of the learning-teaching process.

\section{MATERIAL AND METHOD}

The new teaching approach we have implemented, ELG, came as a natural result of one of the authors' experience (Daniela Larion) in teaching English 
language for more than three years (since 2014) to the students of the Geography Department (Alexandru Ioan Cuza University of Iași), combined with the experience in teaching CLIL in secondary education for two years (Geography in English, at Colegiul Național Iași, 1990, 1991) and in lecturing in English, on geographic topics, in several European universities during teaching visits through the Erasmus programme. At the same time, both authors were involved in the International Geography Olympiad for several years, with the opportunity to develop new strategies for teaching and learning Geography in English, tested during the competitions in which the Romanian students got brilliant results at the international level, one of them being Andra-Cosmina Albulescu herself, who was a gold medalist in 2013 and 2014, at two editions of the International Geography Olympiad.

The implementation of this new teaching concept is based primarily on the systematic observation of the English classes, during three academic semesters (the first and second semester of the 2016-2017 academic year and the first semester of the 2017-2018 academic year), by both authors. The students of the observed group were first and second year students in Geography.

In order to point out the benefits of implementing ELG in the Geography Department, at Alexandru Ioan Cuza University of Iași, specific research methods were used, considering both the qualitative and quantitative approach.

\section{Research Methods and Instruments}

In order to find out if there are relevant differences between traditional English language teaching/learning approach (EL) and ELG, and if the latter one presents any benefits, we used several research methods.

The survey method was used by targeting a group of students of the Department of Geography, at Alexandru Ioan Cuza University of Iași (who attended both EL and ELG classes), using online questionnaires. The survey was conducted in 2017, when these students were in the second year of their Master studies, so they had time to experience the practical use of the English knowledge they had got during Bachelor studies. The questions of the survey referred mainly to the differences between teaching and learning English language through standard EL approach and ELG approach, and the students were required to point out the positives and the negatives. In doing so, the bias was removed, therefore ensuring the relevance and authenticity of the answers. We consider that this method is relevant to accomplish the objective we have in the endeavour of proving that the ELG is a better approach for Geography students.

We also used the semi-structured interview with open-ended questions applied to Ph.D. Geography students, with questions referring to the ways in which they had acquired their English knowledge and to the necessity of improving the approach in teaching English to Geography 
students. This interview had been taken in 2014, before the ELG classes started. The results of this method are relevant in pointing out that a change in the teaching methodology for the Bachelor Geography students is absolutely necessary. Another interview was applied in 2017 to a group of teaching and research staff from the Department of Geography at Alexandru Ioan Cuza University of Iași, as feedback on the textbook we wrote to support the ELG classes.

We consider that these methods are complementary and they cover the needs of our research. Applying these methods to different target groups is an advantage in getting results from a broader perspective.

\section{Participants}

The survey was done by addressing the questionnaire to 65 students who were in their first year of Bachelor studies in 2013 (when English language was taught by a philologist, with traditional English language teaching approach) and in the second year in 2014 (when English language was taught by a geographer with double specialisation - Geography and English language and literature - with ELG approach). As for the students' attendance to the English classes during the $1^{\text {st }}$ and $2^{\text {nd }}$ year, the situation was the following: 15 students had $100 \%$ attendance, 38 students participated at more than $50 \%$ of the classes, while 12 students attended less than $50 \%$ of the English classes. The English language command of these students is differentiated into a hierarchical structure as follows: basic, intermediate, and advanced level.

The interviewees were 9 Ph.D. candidates in the first or second year of their studies, who had already used English language in their professional activity. They all did their Bachelor and Master studies in the Department of Geography and they all attended English classes prior to 2014, therefore taught in a traditional way. Their answers regarding the necessity of another English language teaching approach complemented the results obtained from the previous survey, making it clear that the classical EL model did not suit the practical needs of the Geography students concerning English language skills.

Later on, in 2017, after publishing the textbook English Language for Geography Students (Daniela Larion), we interviewed eight members of the teaching and research staff, including colleagues with professional background in Physical Geography and Human Geography. They all used English language as the main publishing language and also for the lectures they delivered abroad during their Erasmus teaching visits. They all wanted the textbook for themselves, too, appreciating that the structure, content and interactive approach of the book made it a useful tool on any geographer's working desk. 


\section{RESULTS AND DISCUSSIONS}

The main idea of the survey was to find out what the perception of the Geography students was regarding ELG as compared to traditional EL. The results of the survey can be summarised in the following ideas:

1. Each of the 65 students had something positive to point out about the ELG (as compared to EL) (Figure 1). There were four groups of positive characteristics which were obtained by categorising and sorting the students' answers according to a hierarchical structure. As a result, we identified four directions regarding the strengths of the ELG class: the content of the course ( $32 \%$ of the students), the teaching approach $(27 \%)$, the teacher attributes (21\%) and the student interest (20\%).

Each of these directions were analysed from a qualitative point of view, providing a valuable insight on the mindset of the Geography students regarding the differences between the two teaching approaches, with emphasis on the changes produced by the implementation of the ELG.

A. The content of the English course. The students appreciate as very positive the fact that the content of the ELG course is applied to their field of study, so very useful in their professional life; they consider that the content is a novelty which will be very useful in their career; the students are attracted by the interesting topics that are debated during the class; they consider that one of the most important qualities of the content of the course is its originality.

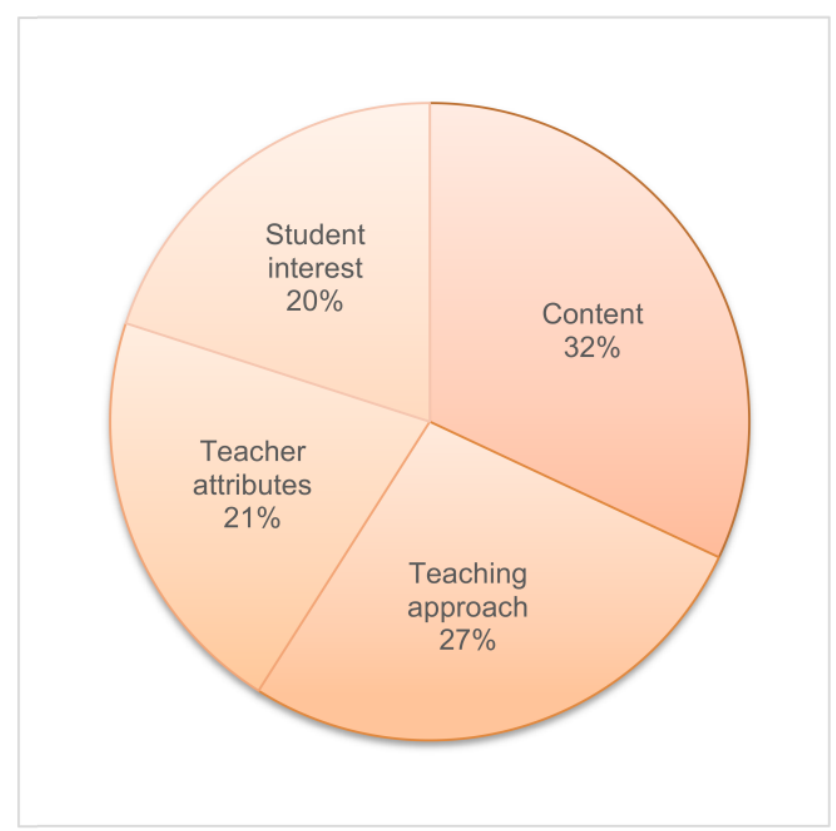

Fig. 1. Positive elements of the ELG course perceived by the students (percentage of the total number of the students who took the survey) 
B. The teaching approach. The students are very happy with the interactive methods used in the teaching and learning process; they are attracted by the use of PowerPoint presentations in which various geographic source materials are used - maps, charts, graphs, tables, images, etc.; the students find it very useful to attend a class in which the structure of the course is very clear, covering all major geographic disciplines, linking the geographic content with grammar and language content, with the aim of improving both geographic skills and English language skills; the students qualified the teaching methods as being very attractive and motivational.

C. The teacher attributes. The students consider that a very important positive aspect of the course is the fact that the teacher is very well prepared professionally and with excellent teaching skills; for many students the passion and attitude of the teacher adds a lot to the quality of teaching; they consider the teacher's optimism and enthusiasm as contagious, with an important role in attracting them to the class and motivating them to study.

D. The student interest and attitude. The students state that they have a great pleasure in attending the English class - even if that was not the case in the previous year when the ELG had not been implemented yet; many students appreciate the fact that they are encouraged to be active during the class; they appreciate the stimulating methods that are used to make them learn more, increasing their motivation to do homework, assignments, projects, presentations - which add points to their final grade.

2. Only $20 \%$ of the students had something negative to point out about the ELG (Figure 2), but even so, some of the elements they mentioned actually had a positive value (such as the small number of classes of English language per week, which indirectly pointed out to the student pleasure in attending such classes because they found them interesting and useful). Other negative aspects pointed out by the students were: the teacher speaking too fast; the teacher using sometimes Romanian language in order to make sure the content was understood by everyone. There were no negative aspects regarding the content and structure of the course or on the teaching methodology.

One of the apparent shortcomings of the ELG is that the applicability of this approach may be reduced by the fact that the teacher who implements it has to posses a double specialisation. Actually, the teacher should master the content elements, which means to be a geographer, and have a very good command of English language, certified by a Bachelor degree in linguistic studies or other form of representative language certificate. Thus, the applicability of the ELG teaching approach is not limited by the implications of the fact that the content teacher and the language teacher is the same person.

From the students' answers regarding the strengths and shortcomings of the ELG class, we may conclude that the students 
appreciate the implementation of this teaching approach, being able to identify and justify its benefits. In this way, they prove to be aware of their own development in the field of English acquisition.

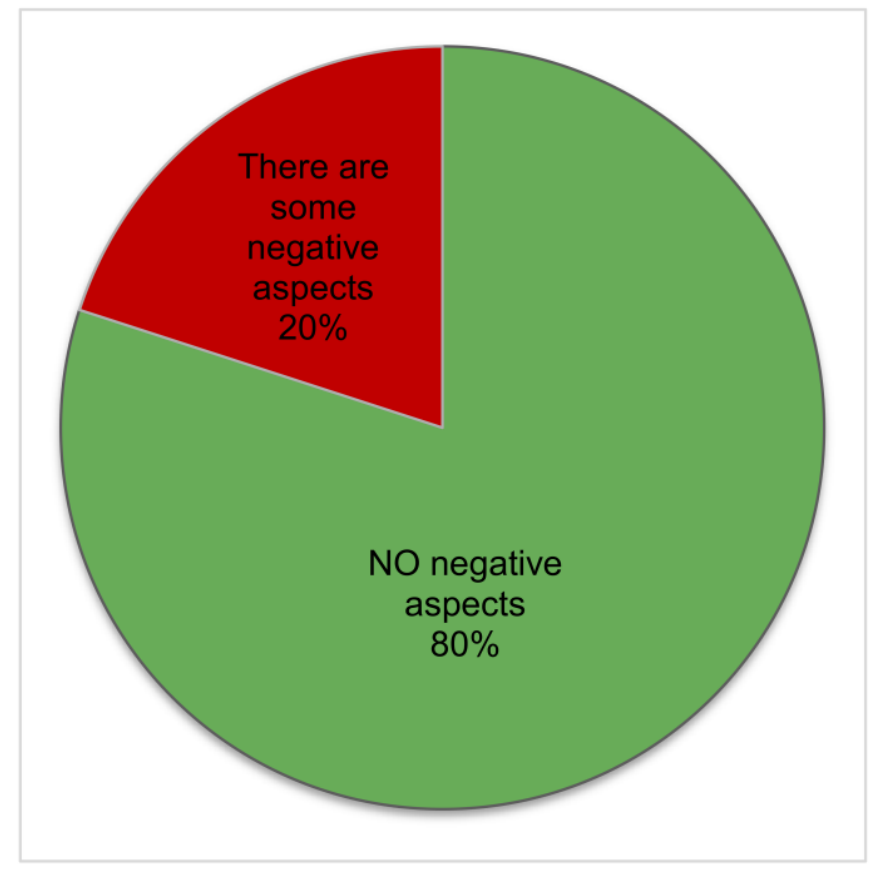

Fig. 2. Negative elements of the ELG course perceived by the students (percentage of the total number of the students who took the survey)

The cumulative results of the research lead to the clear understanding of the fact that the ELG approach is necessary, validating its status as an appropriate, functional, updated and complex way of teaching and learning English language in the geographic academic education.

\section{Discussion on the ELG class}

The main idea of implementing ELG in teaching English language to the students of the Geography Department was that of combining teaching techniques used in Geography with methods used in teaching English, in order to get the best results in the geographic content assimilation and language skills proficiency.

Each ELG course always uses PowerPoint presentations (created by the teacher) due to the significant advantages this method presents. A great variety of geographic tools can be used - maps, images, diagrams, graphs and charts, tables, short video materials on interesting geographic topics - offering an appropriate background for analysis, discussion, questions, interpretations, comparison, essay writing, etc.

Geographic skills are being developed concurrently with English language skills (reading/writing, listening/speaking). It is also through these 
visual presentations that the students are all united, as they are all focused on the same image/map/text, etc.

Using textbooks instead of visual presentations is more likely to separate the students and make it harder for them to follow the same point of interest or understand what phenomenon/process/place the teacher is talking about.

The course will always start with presenting the contents to the students, such as the slide in figure 3a. A quiz on the topic presented in the previous class is usually answered by the students in the beginning, stimulating their critical thinking, their capacity of synthesis and analysis, and then the new topic is revealed (with general geographic information, as well as with a specific case study or an issue of great interest that represents the very attractive part of the course). In the case of the course with the content written on the slide in figure 3a, for example, the point of attraction was represented by exciting information on a new volcanic island (Surtsey), an open laboratory of new lands being formed and life developing in its natural way.

The emphasis on the geographic background for each theme depends very much on the students' level. Sometimes, some parts can be skipped or mentioned briefly in order for other parts to be discussed in detail. The textbook English Language for Geography Students (Daniela Larion, 2017) will provide further information for all those who need it, as it contains a structure covering all the main fields in Geography (Physical Geography, Human Geography, Environmental Science), with a dictionary of geographic terms at the end of each chapter and at the end of the book as well.

During the class, the slides with geographic content usually present a written text next to a representative image/map/diagram, etc., inviting the students to comment on different aspects presented on the slide, to compare, to integrate, and to discover (Figure 3b). The important key words to be memorised by the students are usually written in red (Figures 3c, 3f) and the students are often required to fill in the blanks regarding the definition, location, distribution, and other geographic attributes of those terms.

Although the central theme of each course is represented by a geographic topic (which is deliberately done in order to captivate the students), grammar problems, word-study, language subtleties are always present in the slides (Figure 3d). Many grammar and language exercises are solved either orally or even under the form of a short (3-5 minutes) written test during the class.

The teaching methods ensure a very interactive atmosphere during the class, with many students involved in performing different tasks. The advantage of the double purpose of the course, directed to improving geographic and English language knowledge and skills equally, is that students are encouraged to participate when the activity involves either the use of the geographic knowledge or the English language skills. 


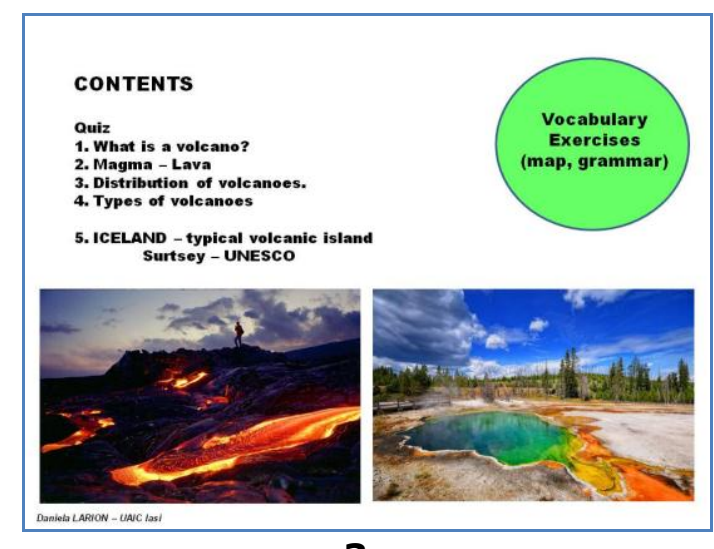

$3 \mathbf{a}$

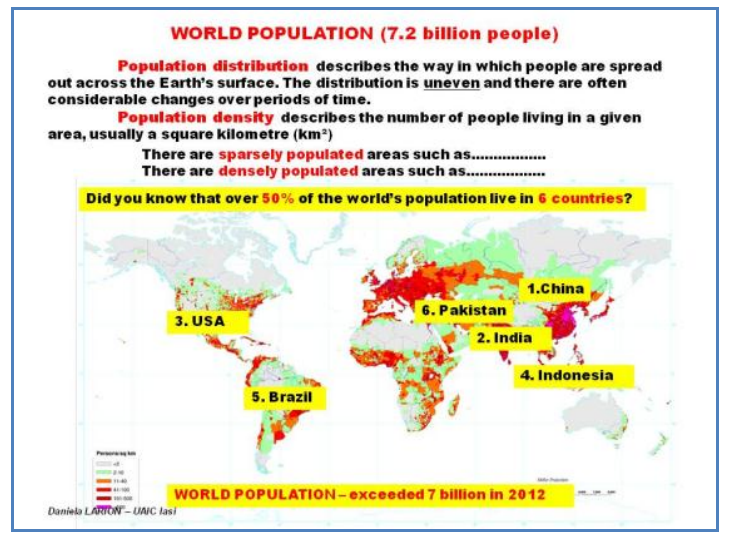

3c

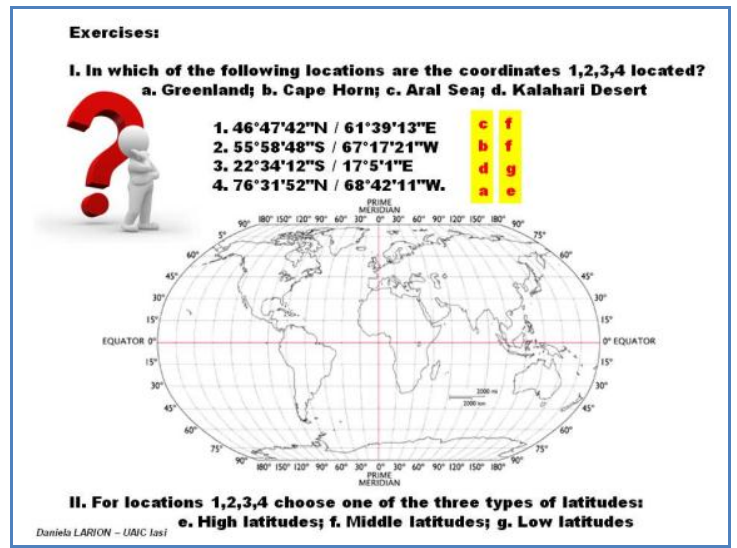

$3 e$

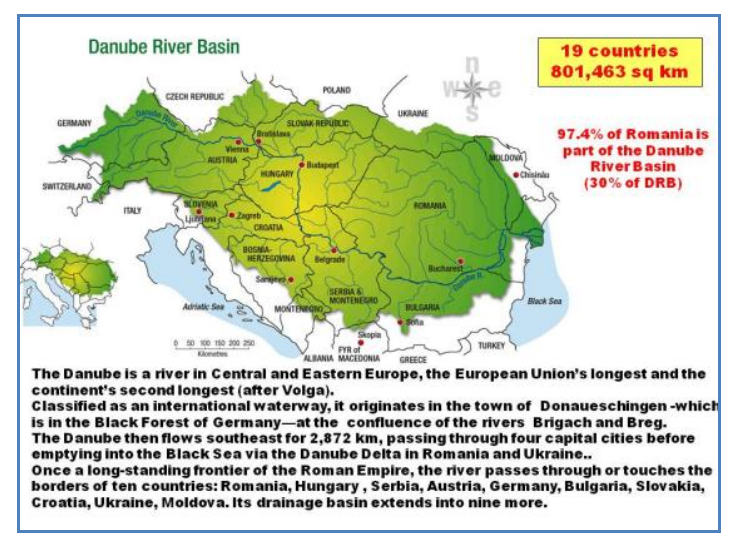

3b

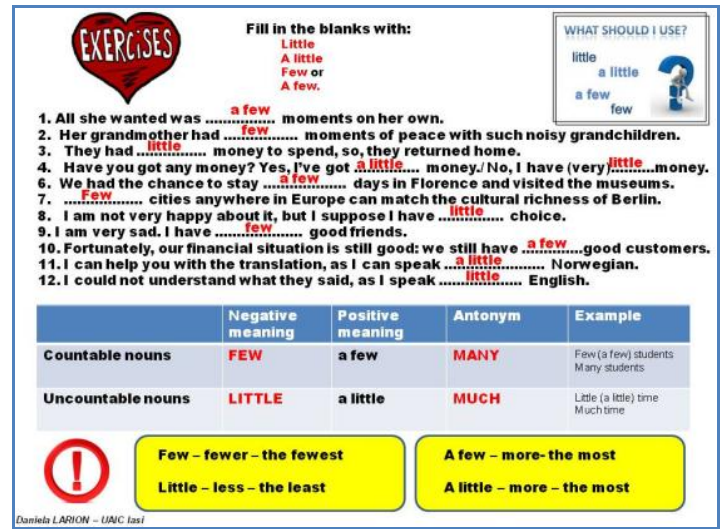

3d

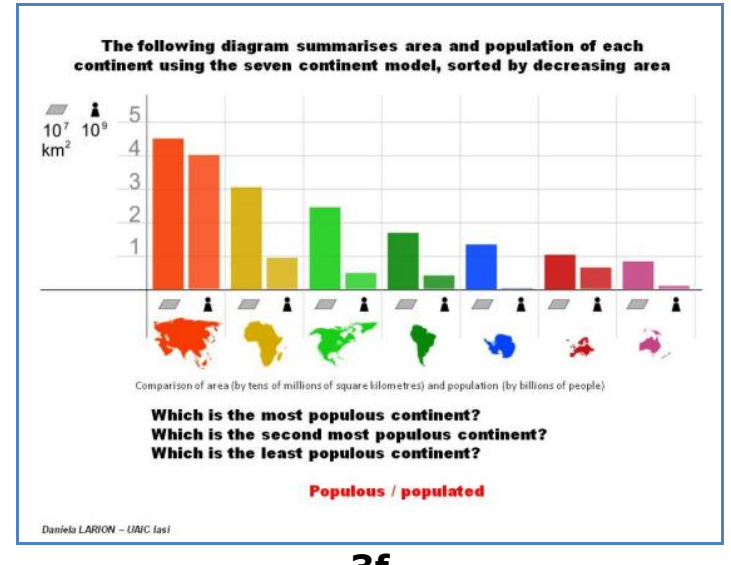

3f

Fig. 3. Samples of slides used in the PowerPoint presentations for teaching English Language for Geography students (during the English classes held by Daniela Larion, 2014-2017, Department of Geography, Alexandru Ioan Cuza University of Iași)

For example, sometimes, the students with a lower English level will be happy to answer the questions with geographic content because it is something they know, and in this way, their geographic knowledge will be a 
link to the acquisition of English knowledge as well as vice versa, with the students with lower geographic knowledge level. The geographic exercises or problems the students are asked to solve usually contain English language and grammar problems that are targeted as well (reading and writing ordinal and cardinal numbers in Figure $3 e$, besides the geographic exercise, adjectives and degrees of comparison in Figure 3f, besides graph reading).

The interdisciplinary character of the course is another characteristic that allows lots of discussions, debates, comments, problem solving, essay writing, showing the connection and interrelations between different fields of science and, at the same time, revealing the role each discipline/subject can have in understanding or learning another one.

It is clear that learning English definitely facilitates the improvement in the geographic knowledge, at the same time with the improvement of the English language skills. Irrespective if we talk about reading/writing skills, or listening/speaking skills, each of them facilitates the access to a way in which the students can grow and develop professionally. They will read more geographic literature in English, they will write better projects, they will participate in different international conferences or scientific events, they will attend lectures that are taught in English, they will apply for study scholarships abroad, they will be more and more integrated in a globalised and internationalised world, with better chances of success in their professional life.

\section{CONCLUSIONS}

The ELG approach proves to be a good choice in teaching English language for Geography students of the Department of Geography, at Alexandru Ioan Cuza University of Iași, due to the following advantages:

1. The geographic content and the English language are equally important and they both play a significant role in evaluation;

2. The content teacher and the language teacher is the same person (the team teaching challenges of CBI are thus removed);

3. The content in ELG is not questionable or negotiable, as it totally fits in the curriculum and covers the needs of the future geographers;

4. Grammar problems are not incidental (as they might be in CLIL) and they are thoroughly planned in order to cover the whole range of basic rules of written and spoken language;

5. ELG is both content-driven and language driven (with benefits for all categories of students, with good or poor level of English or Geography);

6 . There is an increased students' interest to attend the ELG classes and a higher motivation to learn English, due to the attractive topics presented and discussed; 
7. Interactive teaching methods (with a combination of Geography teaching methods and English language teaching methods) give freedom to students in actively participating to the classes and doing assignments;

8. The textbook created and written for ELG represents an important tool in helping the students with lower English language level to fill in the gap in their knowledge, but also a tool for those who need to improve geographic vocabulary and their ability in performing geographic tasks (like reading a map, processing the chart information, interpreting graphical representations, writing geographic essays, reading Geography literature in English, etc.);

9. The ELG classes are very attractive to many international incoming students who study for one semester at Alexandru Ioan Cuza University of Iași;

10. English language represents an important instrument to improve the Geography students' geographic knowledge and skills.

In order to find out more about the advantages (or disadvantages) of using ELG and improve it, we will continue our research, on a qualitative and quantitative basis, in cooperation with specialists from other universities of Romania, where this method is not implemented yet.

\section{References}

Ahmad, S. \& Rao, C. (2013). Applying Communicative Approach in Teaching English as a Foreign Language: a Case Study of Pakistan. Porta Lingarum, 20, 187203.

Banegas, D.L. (2012). Integrating Content and Language in English Language Teaching in Secondary Education: Models, Benefits, and Challenges. Studies in Second Language Learning and Teaching, 2(1), 111-136.

Bradea, L.O. (2007). Comunicarea - Mjiloc și scop în educație. Ed. CDROM, Lucrările Conferinţei Internaţionale "Integrarea Europeană între Tradiţie şi Modernitate" (IETM), ed. II. Târgu Mureş: Universitatea "Petru Maior".

Brinton, D.M. \& Holten, C. (1997). Into, Through, and Beyond: A Framework to Develop Content-Based Material. English Teaching Forum, 35(4), 10, Retrieved 12 December 2017, from http://dosfan.lib.uic.edu/usia/EUSIA/forum/vols/vol35/no4/p10.htm

Brinton, D.M. \& Snow, M.A. (2017). The Evolving Architecture of Content-Based Instruction. In The Content-Based Classroom, 2nd edition (pp. 2-20). Michigan: University of Michigan Press.

Chalikandy, M.A. (2013). A Comprehensive Method for Teaching English for Specific Purpose. Arab World English Journal, 4(4), 310-322.

Corrales, K. \& Maloof, C. (2011). Student perceptions on how content based instruction supports learner development in a foreign language context. Zona próxima. Revista del Instituto de Estudios en Educación, 15, 40-53. 
Dueňas, M. (2004). The Whats, Whys, Hows and Whos of Content-Based Instruction in Second/Foreign Language Education. International Journal of English Studies, 4(1), 73-96.

Flórez, E.G., Díaz, J.J.J. \& Lopera, S.A. (2011). University Students' English Language Improvements through a Content-Based Course. HOW, A Colombian Journal for Teachers of English, 18(1), 73-94.

Genc, B. \& Bada, E. (2005). Culture in Language Learning and Teaching. The Reading Martix, 5(1), 73-84.

Irimiea, S. (2016). English as a Foreign Language. What Challenges Do Teachers of English Face? Studia Universitatis Babeș-Bolyai, Geographia, LXI(1), 145158.

Larion, D. (2017). English Language for Geography Students. Iași: Editura Pim.

Memon, M.A., Abbasi, A.M. \& Umrani T. (2016). A Constrastive Analysis of English Language Teaching Methods. Language in India, 16(9), 267-287.

Richards, J.C. (2006). Communicative Language Teaching Today. Cambridge: Cambridge University Press.

Stakanova, E. \& Tolstikhina, E. (2014). Different Approaches to Teaching English as a Foreign Language to Young Learners. Elsevier. Procedia - Social and Behavioral Sciences, 146, 456-460.

Patridge, B. \& Starfield, S. (eds.) (2013). The Handbook of English for Specific Purposes. Wiley-Blackwell. 